\title{
BACTERIOLOGICAL PROFILE OF DIABETIC FOOT ULCERS
}

\author{
Shajahan Ansar', Ayesha Dastagir ${ }^{2}$
}

${ }_{1}^{1}$ Assistant Professor, Department of Microbiology, Perundurai Medical College, Erode, Tamilnadu, India.

2Senior Assistant Professor, Department of Microbiology, Coimbatore Medical College, Coimbatore, Tamilnadu, India.

\begin{abstract}
BACKGROUND
Diabetes mellitus is a progressive disease, diabetic foot is one of the major complications of diabetes mellitus and eventually leads to development of gangrene and lower extremity amputation. This study has been carried out to detect the antibiotic sensitivity pattern of the isolates in diabetic foot ulcer patients.
\end{abstract}

ABSTRACT

\section{MATERIALS AND METHODS}

This is a descriptive cross-sectional study. Pus and wound swabs were collected from around 100 diabetic patients with foot ulcer who attended the Surgery Out-Patient Department of Coimbatore Medical College Hospital. The samples received in the Department of Microbiology were processed for aerobic culture and antibiotic sensitivity testing during the study period. Blood samples were collected to analyse the HbA1c levels.

\section{RESULTS}

Of the 100 cases studied, most of the patients belonged to the 5th and 6th decades of life (37\%) and (28\%) respectively. Males were more affected compared to females with a ratio of 2.3:1. Maximum number of patients with Diabetic Foot Ulcers were seen in Wagner's Grade II (40 nos.), followed by 38 DFI patients in Wagner's Grade III. Among Gram positive aerobes, Staphylococcus aureus was the predominant isolate (18.4\%). Among Gram negative aerobes, Proteus spp. was the most common isolate (23.2\%) followed by E.coli $16.8 \%$ and Pseudomonas 16\%. Acinetobacter species was the least common isolate (2.4\%). While staphylococcus aureus was the most common among gram positive cocci, proteus was the most common isolate among the gramnegative pathogens.

\section{CONCLUSION}

Staphylococci and Proteus were the two most common isolates detected in diabetic foot infections. There was significant association between DFI and higher HbA1c levels. But no correlation was found between HbA1c levels and the polymicrobial nature of infection in DFI.

\section{KEY WORDS}

Bacteriological Profile, Diabetes, Foot Ulcers.

HOW TO CITE THIS ARTICLE: Ansar S, Dastagir A. Bacteriological profile of diabetic foot ulcers. J. Evolution Med. Dent. Sci. 2018;7(46):4997-5002, DOI: 10.14260/jemds/2018/1112

\section{BACKGROUND}

Diabetes mellitus is a chronic metabolic disorder affecting a large segment of population and also a major public health problem. ${ }^{1}$ Diabetes is rightly called a disease of complications" and "Iceberg disease". India homes 33 million diabetics, ranking highest in the world and has a prevalence of about $8 \%$ in urban India. Twenty percent of all diabetic complications involve feet. ${ }^{2}$

Two major factors are considered important in development of the 'diabetic foot'. One is Peripheral neuropathy causing sensory impairment and weakness of intrinsic muscles of the foot and joint that leads to foot deformities. The other important factor is macro and microangiopathy occurring frequently and leading to ischemia of foot tissues. Wounds become infected five times more often in diabetics than in non-diabetic patients.

'Financial or Other Competing Interest': None.

Submission 24-09-2018, Peer Review 25-10-2018,

Acceptance 31-10-2018, Published 12-11-2018.

Corresponding Author:

Dr. Ayesha Dastagir,

6/23, Servai Nagar,

Thanjavur-4,

Tamilnadu, India.

E-mail: drdayesha@gmail.com

DOI: $10.14260 /$ jemds $/ 2018 / 1112$
Selecting appropriate antimicrobial therapy for diabetic foot infections requires knowledge of likely etiologic agents 3 . The most important characteristic of diabetic foot infection is its polymicrobial nature, and frequent involvement of anaerobes synergistically with aerobes. 1,3

The common aerobic organisms encountered are S. aureus, Proteus species, Pseudomonas, Escherichia coli, Klebsiella species, Coagulase Negative Staphylococci etc. Pepto-streptococcus species, Bacteroides melaninogenicus and Bacteroides fragilis are commonly isolated anaerobes. 4,5 The Incidence of aerobic infection is more in lower grades of Wagner's classification. As the grade increases anaerobic infections are encountered frequently.6,7 About 10-30\% of diabetic patients with foot ulcers will eventually progress to amputation, which may be minor (Foot sparing) or major (Amputation). ${ }^{5}$ Conversely, an infected foot ulcer precedes $\sim 60 \%$ of amputations, making infections perhaps important proximate cause of this tragic outcome. ${ }^{8}$ Mild or non-limb threatening infections can be treated with oral antibiotics, surgical debridement of necrotic tissue, local wound care and close surveillance for progression of infection thus preventing the emergence of complications.

In spite of a multidisciplinary foot-care team to optimize foot care, deleterious effects of infection on soft tissue and bone continue to be a major problem in diabetic patients 9 . Progress of infection is usually associated with delayed 
diagnosis, underestimation of the extent of infection, and inappropriate antimicrobial therapy. ${ }^{3}$ The present study was undertaken to study the prevalence of diabetic foot ulcers in various age groups and gender and to identify the bacterial isolates causing diabetic foot ulcers. Though anaerobic bacteria are also encountered in diabetic infections, isolation of anaerobes was not feasible due to lack of facilities.

This study has been carried out to detect the antibiotic sensitivity pattern of the isolates and MRSA. The antimicrobial spectrum of these isolates would assist clinicians to select appropriate antimicrobial therapy in order to prevent the dreaded complications of diabetic foot infections.

\section{MATERIALS AND METHODS}

The present descriptive cross-sectional study was conducted in the Department of Microbiology at Coimbatore Medical College Hospital over a period of 11/2 years from March 2009 to Sep 2010. Pus and wound swabs were collected from around 100 diabetic patients with foot ulcer attending the Surgery Out-Patient Department. Individuals with age above 20 years with Type I and Type II Diabetes mellitus having Diabetic Foot Ulcer Grade I to V of Wagner's Classification were included in this study. Patients on antibiotic treatment and with non-diabetic ulcers were excluded from the study. The samples received in the Department of Microbiology were processed for aerobic culture and antibiotic sensitivity testing during the study period. Blood samples were collected to analyse the $\mathrm{HbA}_{1} \mathrm{c}$ levels.

Patients were evaluated, and the data was collected with the help of questionnaire which comprised of relevant clinical history, clinical examination and laboratory investigations. Clinical examinations involved evaluating the site, nature and extent of the wound. The ulcer type was evaluated using Wagner's classification of diabetic foot ulcers. This classification includes 6 stages of severity.9,10

\section{Sample Collection}

The surrounding area of the ulcer was cleaned with spirit or povidone iodine and the surface of the wound was washed with sterile normal saline using a sterile cotton swab. Superficial dead tissue and slough was removed with sterile scissors and scalpel. Pus and wound exudates were then obtained with two sterile cotton swabs. One swab was inoculated into Brain heart infusion broth immediately after collection at the bedside for aerobic culture and labelled. Direct smears were made from another swab and stained with Gram stain. The smear was screened for the presence of inflammatory cells and the type of microbial flora. Blood sample was collected under strict aseptic precautions from anterior cubital vein and added to an EDTA containing vacutainer and sent for Blood HbA1c analysis.

\section{Characterization of Bacterial Isolates Culture of Aerobic Bacteria}

The inoculated Brain heart infusion broth was incubated overnight at $37^{\circ} \mathrm{C}$ in an incubator. The broth was then sub cultured onto 5\% Sheep blood agar, MacConkey agar and nutrient agar plates. The colonies were examined under magnifying lens for colony morphology, and the isolates were identified using the standard microbiological procedures like
Gram staining and biochemical reactions as described in Practical Microbiology of Mackie McCartney $14^{\text {th }}$ edition. ${ }^{11}$

\section{Antibiotic Susceptibility Testing}

Antibiotic susceptibility testing was done by Kirby Bauer disc diffusion method as per CLSI guidelines. The isolates were grown in peptone water by incubating at $370 \mathrm{C}$ till the turbidity matched that of 0.5 McFarland standard. They were then lawn cultured onto Mueller Hinton agar plate and commercial antibiotic discs [Penicillin (10 U), Erythromycin (15 $\mu \mathrm{g})$, Ampicillin $(10 \mu \mathrm{g})$, Amoxyclav $(30 \mu \mathrm{g})$, Gentamicin $(10 \mu \mathrm{g})$, Amikacin $(30 \mu \mathrm{g})$, Linezolid $(10 \mu \mathrm{g})$, Cefotaxime (30 $\mu \mathrm{g})$, Cephalexin $(30 \mu \mathrm{g})$, Ciprofloxacin $(5 \mu \mathrm{g})$, Vancomycin (30 $\mu \mathrm{g})$, Co-trimoxazole $(25 \mu \mathrm{g})]$ procured from $\mathrm{Hi}$ media, Mumbai were placed on the surface. The plates were incubated overnight at $37^{\circ} \mathrm{C}$ and the zones of inhibition were measured and interpreted according to the charts provided by the manufacturers. ${ }^{12}$ Staphylococcus aureus ATCC 25923 was used as a control for the susceptibility testing.

Staphylococcus aureus isolates were subjected to Methicillin susceptibility testing by Kirby-Bauer disc diffusion method using Oxacillin ( $1 \mu \mathrm{g})$ disc. 1 to 2 Staphylococcal colonies were suspended in $0.5 \mathrm{ml}$ of sterile normal saline and the turbidity matched to 0.5 McFarland. Using sterile cotton swab the broth culture was uniformly streaked on to Mueller Hinton agar with $2 \%$ Sodium Chloride Plate. Oxacillin $(1 \mu \mathrm{g})$ disc was placed on the plates were incubated at $37^{\circ} \mathrm{C}$ aerobically for $24 \mathrm{hrs}$ and the zone of inhibition was measured. Staphylococcus aureus ATCC 43300 was used as a control for methicillin resistance.

The Non-fermenters are identified based on the nonlactose fermenting colonies on MacConkey agar plate. Antimicrobial susceptibility testing was performed by Kirby Bauer disk diffusion method. Commercially available Mueller Hinton agar culture medium and antibiotic discs (Himedia) were used. The zones of inhibition were measured and interpreted according to the charts provided by the manufacturers. ${ }^{12}$

\section{Statistical Analysis}

Descriptive statistics calculated for all the variables in this study and reported as proportions and percentages.

\section{RESULTS}

The present study was carried out in the Department of Microbiology, CMC from March 2009 to Sep 2010 to look for the pattern of growth of aerobic organisms and their antibacterial susceptibility pattern in diabetic foot infections. The following Tables and Figures illustrate the results in detail.

\begin{tabular}{|c|c|c|}
\hline Age in Years & Males & Females \\
\hline $21-30$ & 3 & 1 \\
\hline $31-40$ & 4 & 1 \\
\hline $41-50$ & 14 & 4 \\
\hline $51-60$ & 26 & 11 \\
\hline $61-70$ & 16 & 12 \\
\hline $71-80$ & 7 & 1 \\
\hline Total & $\mathbf{7 0}$ & $\mathbf{3 0}$ \\
\hline \multicolumn{3}{|c|}{ Table 1. Age and Sex Distribution of Diabetic Foot Ulcer } \\
Cases \\
\hline
\end{tabular}


Of the 100 cases studied, most of the patients belonged to the $5^{\text {th }}$ and $6^{\text {th }}$ decades of life (37\%) and (28\%) respectively. Males were more affected compared to females with a ratio of 2.3:1.

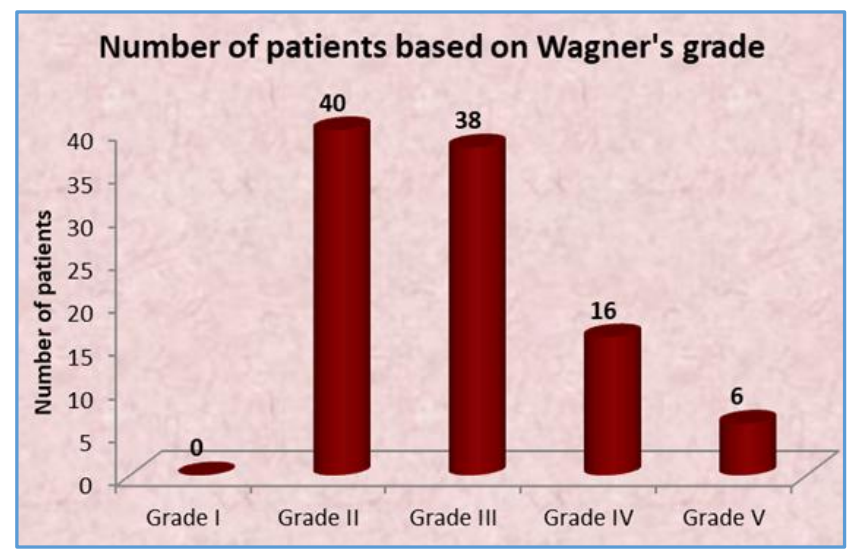

\section{Chart 1. Distribution of Ulcers according to Wagner's Classification}

Distribution of Ulcers According to Wagner's Classification are listed in Chart 1. Maximum number of patients with Diabetic Foot Ulcers were seen in Wagner's Grade II (40 nos.), followed by 38 DFI patients in Wagner's Grade III.

\begin{tabular}{|c|c|c|c|}
\hline $\begin{array}{c}\text { Wagner's } \\
\text { Grade }\end{array}$ & $\begin{array}{c}\text { Number } \\
\text { of Patients }\end{array}$ & $\begin{array}{c}\text { Number of } \\
\text { Organisms } \\
\text { Isolated } \\
\text { (Aerobes) }\end{array}$ & $\begin{array}{c}\text { Average } \\
\text { Number of } \\
\text { Micro } \\
\text { Organisms/ } \\
\text { Sample }\end{array}$ \\
\hline Grade I & 0 & 0 & 0 \\
\hline Grade II & 40 & 40 & 1 \\
\hline Grade III & 38 & 40 & 1.5 \\
\hline Grade IV & 16 & 35 & 2.18 \\
\hline Grade V & 6 & 10 & 1.66 \\
\hline Table 2. Distribution of Bacterial Isolates in Correlation \\
with Wagner's Grade \\
\hline
\end{tabular}

Average no of aerobes per sample was found to be maximum in Grade 4 ulcers (2.18). The average number of microorganisms/sample is decreasing as the Wagner's grade Decreases. The numbers of isolates are more than the number of samples and the average number of microorganisms/sample is more than one because of poly microbial growth yield. Hundred pus samples were collected from foot ulcers of diabetic patients and assessed for the growth of aerobic organisms. Out of the hundred samples 90 yielded aerobic bacterial growth. Out of the 90 culture positive samples mono microbial growth was found in 62 samples and 28 samples yielded polymicrobial growth with a percentage of 69 and 31 respectively.

\begin{tabular}{|c|c|c|}
\hline $\begin{array}{l}\text { Gram Positive } \\
\text { Isolates }\end{array}$ & $\begin{array}{l}\text { No. of Aerobes } \\
(n=125)\end{array}$ & (\%) \\
\hline Staphylococcus aureus & 23 & 18.4 \\
\hline $\begin{array}{l}\text { Coagulase negative Staphylococcus } \\
\text { ( CONS) }\end{array}$ & 8 & 6.4 \\
\hline Enterococcus faecalis & 1 & 0.8 \\
\hline \multicolumn{3}{|l|}{ Gram Negative Isolates } \\
\hline Proteus spp. & 29 & 23.2 \\
\hline Pseudomonas aeruginosa & 20 & 16 \\
\hline E.coli & 21 & 16.8 \\
\hline Klebsiella spp. & 11 & 8.8 \\
\hline Enterobacter spp. & 5 & 4 \\
\hline Citrobacter freundii & 4 & 3.2 \\
\hline Acinetobacter spp. & 3 & 2.4 \\
\hline \multicolumn{3}{|c|}{ Table 3. Distribution of Bacterial Isolates } \\
\hline
\end{tabular}

Distribution of aerobic bacterial isolates are listed as per Table 3. Among Gram positive aerobes, Staphylococcus aureus was the predominant Isolate (18.4\%). Among Gram negative aerobes, Proteus spp. was the most common isolate (23.2\%) followed by E.coli $16.8 \%$ and Pseudomonas $16 \%$. Acinetobacter species was the least common isolate (2.4\%).

\begin{tabular}{|c|c|c|c|c|c|c|}
\hline Antibiotics & \multicolumn{5}{|c|}{ Number of Susceptible Isolates } \\
\hline & $\begin{array}{c}\text { Staphylococcus } \\
\text { aureus(13) }\end{array}$ & \multicolumn{2}{|c|}{ CONS(6) } & $\begin{array}{c}\text { Enterococcus } \\
\text { fecalis(1) }\end{array}$ \\
\hline & No & \% & No. & $\%$ & & \\
\hline $\mathrm{Ak}$ & 16 & $69.5 \%$ & 4 & $66.6 \%$ & - & - \\
\hline $\mathrm{G}$ & 10 & $43.4 \%$ & 2 & $33 \%$ & - & - \\
\hline $\mathrm{Am}$ & 6 & $26.08 \%$ & 2 & $33 \%$ & 0 & 0 \\
\hline $\mathrm{Cip}$ & 11 & $47.8 \%$ & 3 & $50 \%$ & 0 & 0 \\
\hline Of & 12 & $52.2 \%$ & 3 & $50 \%$ & 0 & 0 \\
\hline $\mathrm{Cp}$ & 1 & $4.3 \%$ & 1 & $16.6 \%$ & 0 & 0 \\
\hline $\mathrm{Ce}$ & 6 & $26.08 \%$ & 2 & $33.3 \%$ & 0 & 0 \\
\hline $\mathrm{E}$ & 8 & $34.7 \%$ & 1 & $16.6 \%$ & 0 & 0 \\
\hline $\mathrm{Do}$ & 6 & $26.08 \%$ & 2 & $33 \%$ & - & - \\
\hline Ac & 12 & $52.2 \%$ & 4 & $66 \%$ & 0 & 0 \\
\hline Co & 2 & $8.6 \%$ & 1 & $16.6 \%$ & 0 & 0 \\
\hline Lz & 23 & $100 \%$ & 6 & $100 \%$ & 1 & - \\
\hline Van & 23 & $100 \%$ & 6 & $100 \%$ & 1 & - \\
\hline Table 4. Antimicrobial Susceptibility Pattern of Gram- \\
\hline \multicolumn{7}{|c|}{ Positive Cocci } \\
\hline
\end{tabular}

Table 4 shows the Antimicrobial Susceptibility Pattern of Gram-Positive Cocci. Staphylococcus aureus showing sensitivity of $26 \%$ to Cefotaxime, $52 \%$ to Ofloxacin and Amoxyclav \& $47.8 \%$ to Ciprofloxacin. CONS isolates are $66 \%$ sensitive to Amikacin. And all these isolates show 100\% sensitivity to Vancomycin and Linezolid.

\begin{tabular}{|c|c|c|c|c|c|c|c|c|c|c|c|c|c|}
\hline AEROBES & Cot & Amp & Ak & G & Cip & Of & Caz & Ctx & $\mathbf{C i}$ & $\overline{\mathbf{A c}}$ & Cfs & Pit & Mrp \\
\hline \multirow[t]{2}{*}{ Proteus } & 10 & 4 & 13 & 11 & 15 & 20 & 13 & 22 & 24 & 8.4 & 24 & 29 & - \\
\hline & $34 \%$ & $15 \%$ & $46 \%$ & $34 \%$ & $53 \%$ & $69 \%$ & $46 \%$ & $76 \%$ & $84 \%$ & $26 \%$ & $84 \%$ & $100 \%$ & \\
\hline \multirow{2}{*}{$\begin{array}{l}\text { Pseudomonas } \\
\text { Spp.(14) }\end{array}$} & - & 0 & 2 & 2 & 9 & 9 & 10 & 9 & 8 & 11 & 14 & 19 & 19 \\
\hline & & & $10.5 \%$ & $10.5 \%$ & $47 \%$ & $47 \%$ & $52 \%$ & $47 \%$ & $42 \%$ & $57 \%$ & $68 \%$ & $94 \%$ & $100 \%$ \\
\hline \multirow{2}{*}{ E.coli(15) } & 2 & 11 & 17 & 12 & 10 & 7 & 9 & 16 & 15 & 6 & 21 & 21 & -- \\
\hline & $11 \%$ & $52 \%$ & $82 \%$ & $58 \%$ & $47 \%$ & $42 \%$ & $47 \%$ & $76 \%$ & $70 \%$ & $29 \%$ & $100 \%$ & $100 \%$ & \\
\hline \multirow{2}{*}{$\begin{array}{c}\text { Klebsiella } \\
\text { pneumoniae }(10)\end{array}$} & 1 & 3 & 6 & 6 & 11 & 10 & 7 & 7 & 7 & 4 & 4 & 11 & - \\
\hline & $12.50 \%$ & $25 \%$ & $50 \%$ & $50 \%$ & $100 \%$ & $87.5 \%$ & $62.5 \%$ & $62.5 \%$ & $62.5 \%$ & $37.5 \%$ & $87.5 \%$ & $100 \%$ & \\
\hline Enterobacter Spp(5) & 2 & 2 & 3 & 2 & 5 & 5 & 3 & 4 & 4 & 3 & 5 & 5 & - \\
\hline
\end{tabular}




\begin{tabular}{|c|c|c|c|c|c|c|c|c|c|c|c|c|c|}
\hline & $40 \%$ & $40 \%$ & $60 \%$ & $40 \%$ & $100 \%$ & $100 \%$ & $60 \%$ & $80 \%$ & $80 \%$ & $60 \%$ & $100 \%$ & $100 \%$ & \\
\hline \multirow{2}{*}{$\begin{array}{l}\text { Citrobacter } \\
\text { freundii( } 4 \text { ) }\end{array}$} & 2 & 3 & 3 & 3 & 3 & 3 & 3 & 4 & 4 & 3 & 4 & 4 & - \\
\hline & $50 \%$ & $75 \%$ & $75 \%$ & $75 \%$ & $75 \%$ & $75 \%$ & $75 \%$ & $100 \%$ & $100 \%$ & $75 \%$ & $100 \%$ & $100 \%$ & \\
\hline \multirow{2}{*}{$\begin{array}{c}\text { Acinetobacter } \\
\text { Spp. }{ }^{(3)}\end{array}$} & 1 & 1 & 3 & 2 & 3 & 3 & 2 & 2 & 2 & 2 & 3 & 3 & - \\
\hline & $33.30 \%$ & $33.30 \%$ & $100 \%$ & $50 \%$ & $100 \%$ & $100 \%$ & $66 \%$ & $66 \%$ & $66 \%$ & $66 \%$ & $100 \%$ & $100 \%$ & \\
\hline
\end{tabular}

Proteus spp. showed $100 \%$ sensitivity to Piperacillin with tazobactam, $84 \%$ to Cefoperazone with sulbactam and Ceftriaxone, $76 \%$. sensitivity to Cefotaxime, $53 \%$ to Ciprofloxacin and $46 \%$ to amikacin. Pseudomonas spp. showed $100 \%$ sensitivity to Meropenem followed by $94 \%$ to Piperacillin with tazobactam, 68\% to Cefoperazone with sulbactam, $52 \%$ to Ceftazidime, and $47 \%$ to Ciprofloxacin. Amikacin and Gentamicin showed $10.5 \%$ sensitivity.

Escherichia coli showed highest sensitivity to Piperacillin with tazobactam and Cefoperazone with sulbactam, $82 \%$ to amikacin, $76 \%$ to Cefotaxime and Ceftriaxone (70\%) and $47 \%$ to Ceftazidime.

\begin{tabular}{|c|c|c|c|}
\hline Organism & $\begin{array}{c}\text { Total No. } \\
\text { Isolated }\end{array}$ & $\begin{array}{c}\text { Methicillin } \\
\text { Resistant } \\
\text { Staphylococci }\end{array}$ & $\begin{array}{c}\text { Methicillin } \\
\text { Sensitive } \\
\text { Staphylococci }\end{array}$ \\
\hline $\begin{array}{c}\text { Staphylococcus } \\
\text { aureus }\end{array}$ & 23 & 12 & 11 \\
\hline CONS & 6 & 3 & 3 \\
\hline Table 6. Distribution of Methicillin Sensitive \& Methicillin \\
Resistant Staphylococci \\
\hline
\end{tabular}

As evident from Table 6, antimicrobial susceptibility testing revealed the methicillin resistance. Among 23 Staphylococcus aureus isolates 12 were Methicillin resistant (55\%) and 11 were methicillin sensitive. CONS isolates exhibited 50\% Methicillin resistance.

\section{DISCUSSION}

Diabetic foot infection is considered as one of the most threatening and disabling complication for a diabetic patient as the lesions of the extremities can become so severe that the patient may risk the amputation of the toe, foot or leg. ${ }^{4,12}$ Hundred pus and wound samples were collected from patients above 20 years of age with known history of Diabetes mellitus.

In the present study the highest average no of isolates per sample was found in Grade 4 ulcers (2.18). In a prospective study of Diabetic foot ulcers conducted by Ekta Bansal et.al. an average of 1.52 isolates per case was reported. ${ }^{3}$ But here the maximum number of isolates per case was reported from Grade II. In Uday Kelkar et al study in $2004{ }^{16}$ an average of 3.7 organisms were yielded per sample. The yield from the deep tissue samples was significantly higher than the yield from surface swab samples.

Our study showed $31 \%$ of polymicrobial infections similar to Ekta Bansal et al study ${ }^{3}$ showing 35\% polymicrobial infection. In Contrast polymicrobial growth was noted as $64.4 \%$ in a study conducted by C.Aanandi et.al, from Tamil Nadu India. ${ }^{1}$ Out of the 427 positive cultures $83.8 \%$ were polymicrobial, in a clinical trial conducted by Diane M Ceitron et al, at R.M.Alden Research Laboratories California ${ }^{17}$. It's because the maximum number of patients in these two studies belonged to Wagner's Grade III, but in our study the maximum number of patients with polymicrobial growth were in the Wagner's Grade II.
In our study among the enterobacteriaceae isolates, Proteus mirabilis was the most common isolate $(23.2 \%)$ followed by E.coli (16.87\%) \& Klebsiella 8.8\%. Citrobacter freundii was the least common isolates belonging to the enterobacteriaceae family which is similar to the study by Uday Kelkar et al (2004) ${ }^{16}$ Proteus mirabilis, Escherichia coli, Pseudomonas aeruginosa, Klebsiella species and Enterococcus species were organisms isolated in decreasing order.

But in Ami Variyae et al study Klebsiella pneumonia (59.7\%) was the most common isolate followed by E.coli $40.29 \% .{ }^{18}$ Similar results were shown in a study conducted by Emily. S. Bomasang et al. with $45.8 \%$ of E. coli 19 .

In a study by Ashwin N Anantha Krishnan Et al. $21 \%$ of E. coli were isolated ${ }^{18}$. This difference in common isolate in different studies might be due to different grade of ulcers selected. In our study among the non-enterobacteriaceae Pseudomonas $(16 \%)$ was the highest isolate, Acinetobacter species was the least common isolate (2.4\%). In a study conducted by Vishwanath et $\mathrm{al}^{15}$ Pseudomonas species was accounting for $17 \%$ of the isolates which is similar to our study. Pseudomonas aeruginosa was the most common isolate accounting for $21.7 \%$ in Ekta Banzal et al study. ${ }^{3}$

Staphylococcus aureus showing sensitivity of $26 \%$ to Cefotaxime, $47.8 \%$ to Ciprofloxacin and $52 \%$ to Ofloxacin and Amoxyclav. CONS isolates are $66 \%$ sensitive to Amikacin and $100 \%$ sensitive to Vancomycin. And all these isolates show $100 \%$ sensitivity to Vancomycin and Linezolid. Out of the 23 Staphylococcus aureus isolates 12 isolates were methicillin resistant (55\%) and 11 isolates were found to be MSSA

(45\%). In a study by C.N. Dang et al ${ }^{20}$ MRSA was $30.2 \%$. $42.86 \%$ of MRSA was seen in a study conducted by Murugan S. et al ${ }^{13}$ while assessing the prevalence of MRSA among diabetic Ulcer patients which correlates with our study.

In our study MRSA were $100 \%$ resistant to Ampicillin, $65 \%$ to Erythromycin \& $70 \%$ to Cephalexin. $100 \%$ sensitivity was noted to Vancomycin and Linezolid. In a study by Sivaram Uma Devi Et al. 65\% of the 29 Staphylococcus aureus isolates were found to be methicillin resistant. ${ }^{13}$ Resistance to Penicillin was $100 \%$, Erythromycin was $31 \%$. And Gentamicin was 59\%. Sensitivity was higher to Vancomycin. They were of the opinion that combination of Vancomycin and Linezolid for coverage of Gram-Positive Cocci could be used empirically and then tailored to the needs of the individual once susceptibility testing report was available.

In our study, Proteus spp. (23.2\%) was the major gramnegative aerobe isolated which showed $100 \%$ sensitivity to Piperacillin, $84 \%$ to Cefoperazone with sulbactam and Ceftriaxone, $76 \%$ sensitivity to Cefotaxime, $53 \%$ to Ciprofloxacin and for amikacin $46 \%$ sensitivity. It showed lowest sensitivity to Ampicillin (15\%). In a study by Ekta Bansal et al $^{3}$ in 2009 Proteus sp exhibited 100\% sensitivity to Cefoperazone with sulbactam and Ceftriaxone, and amikacin. It showed lowest sensitivity to Amoxicillin (33\%). In a study 
by Vimalin Hena et al in 2010 the proteus isolate was $71 \%$ sensitive to Ciprofloxacin $57 \%$ to Amikacin.

In our study Pseudomonas spp. showed 100\% sensitivity to Meropenem followed by $94 \%$ to Piperacillin with tazobactam, $68 \%$ to Cefoperazone with sulbactam, $52 \%$ to Ceftazidime, $47 \%$ to Ciprofloxacin, Amikacin and Gentamicin showed $10.5 \%$ sensitivity. In a study by Ekta Bansal et al in 2009 Pseudomonas showed $100 \%$ sensitivity to Imipenem, $94 \%$ to to Ceftazidime, $83 \%$ to Piperacillin $63 \%$ to Ciprofloxacin. For Amikacin 79\% and Gentamicin 33\% sensitivity was noticed. ${ }^{3}$ In a study by Vimalin Hena et al in 2010 study Pseudomonas sp showed 100\% sensitivity to Imipenem followed by $83 \%$ to Piperacillin, $41 \%$ to Ceftazidime and $22 \%$ to Ciprofloxacin. ${ }^{21}$

In our study Escherichia coli showed highest sensitivity to Piperacillin with tazobactam and Cefoperazone with sulbactam, $82 \%$ to amikacin, $76 \%$ to Cefotaxime and Ceftriaxone (70\%) and $47 \%$ to Ceftazidime. In a study by Ekta Bansal et al in 2009 study Escherichia coli showed 96\% sensitivity to Cefoperazone with Sulbactam, $90 \%$ to Amikacin, $82 \%$ to Ceftazidime and 33\% to Ciprofloxacin. ${ }^{10}$ In a study by Vimalin Hena et al in 2010 study Escherichia coli showed $71 \%$ sensitivity to Piperacillin followed by $65 \%$ to Ceftazidime. For Amikacin, Gentamicin and Cefotaxime 59\% sensitivity was noticed.

Anandi et al ${ }^{1}$ observed that all the aerobes were sensitive to amikacin and gentamicin except two Pseudomonas sp isolates. All the aerobes were susceptible to Cefotaxime except four Pseudomonas spp. isolates which were susceptible to amikacin and gentamicin. Dipali AC et al found that more than $70 \%$ of the aerobic gram-negative bacilli were sensitive to aminoglycosides, amikacin (95.74\%) and gentamicin $(70.21 \%)$.

Sensitivity to Cefotaxime was $63.50 \%$. Nema et al 22 found that the gram-negative bacilli were most sensitive to aminoglycosides and sensitivity to Cefotaxime was $63.12 \%$.

\section{CONCLUSION}

Diabetic foot ulcers are one of the most common and dreaded complications of diabetes mellitus. It is more common among males in the 5th and 6th decades of life. As the Wagener's grade increased, the prevalence of infections also increased. Monomicrobial infections prevailed over polymicrobial infections. While staphylococcus aureus was the most common among gram positive coccus, Proteus was the most common isolate among the gram-negative pathogens.

The Gram-negative bacterial isolates were highly sensitive to piperacillin with tazobactam followed by cefoperazone with sulbactam. Pseudomonas aeruginosa showed highest sensitivity to meropenem. Staphylococcus aureus showed 55\% methicillin resistance (MRSA).

Foot problems in diabetes continue to persist and will be challenging the clinicians. They can be properly treated by proper and prompt antibiotic therapy to optimize patient care and to improve clinical outcome.

\section{REFERENCES}

[1] Anandi C, Alaguraja D, Natarajan V, et al. Bacteriology of diabetic foot lesions. Indian J Med Microbiol 2004;22(3):175-8.

[2] Gaur DS, Verma A, Gupta P. Diabetic foot in Uttaranchal. J K Science 2007;9(1):18-20.
[3] Bansal E, Garg A, Bhatia S, et al. Spectrum of microbial flora in diabetic foot ulcers. Indian Journal of Pathology and Microbiology 2008;51(2):204-8.

[4] Chincholikar DA, Pal RB. Study of fungal and bacterial infections of the diabetic foot. Indian $\mathrm{J}$ Pathol Microbiol 2002;45(1):15-22.

[5] Wheat LJ, Allen SD, Henry M, et al. Diabetic foot infections - bacteriological analysis. Arch Intern Med 1986;146(10):1935-40.

[6] Ramani A, Ramani R, Shivananda PG, et al. Bacteriology of diabetic foot ulcers. Indian J Pathol Microbiol 1991;34(2):81-7.

[7] Pathare NA, Bal A, Talvalkar GV, et al. Diabetic foot infections: a study of microorganisms associated with the different Wagner grades. Indian J Pathol Microbiol 1998;41(4):437-41.

[8] Lipsky BA. Medical treatment of diabetic foot infections. Clinical Infectious Disease 2004;39(Suppl 2):S104-S14.

[9] Bunn HF. Haney DN, Kamin S, et al. The biosynthesis of human haemoglobin A1c. Slow glycosylation of haemoglobin in vivo. J Clinic Invest 1976;57(6):16529.

[10] Wagner FW. Algorithms of diabetic foot care. In: Levin ME, O'Neal FW, eds. The diabetic foot. St. Louis: DV Mosby 1983: p. 291.

[11] Alberti KGMM, Defronzo RA, Keen H, et al. The diabetic foot. Chapter - 68. International textbook of diabetes mellitus. Vol. 2. 1992: p. 1535.

[12] Wayne PA. National Committee for clinical laboratory standards. Performance standards for antimicrobial disc susceptibility testing, 12th information supplement, M100-S12, 2002.

[13] Murugan S, Mani KR, Umadevi P. Prevalence of methicillin resistant staphylococcus aureus among diabetic patients with foot ulcers and their antimicrobial susceptibility pattern. Journal of Clinical Diagnostics and Research 2008;2(4):979-84.

[14] Ananthakrishnan AN, Kanugo R, Angamuthu K, et al. Detection of extended spectrum beta lactamase producers among surgical wound infections and burns patients in JIPMER. Indian Journal of Medical Microbiology 2000;18(4):160-5.

[15] Vishwanathan V, Jasmine JJ, Snehalatha C, et al. Prevalence of pathogens in diabetic foot infection in South Indian type 2 diabetic patients. Journal of Association of Physicians India 2002;50:1013-6.

[16] Kelkar U, Kagal A. Bacteriology of diabetic ulcers: effect of sample collection method. The diabetic Foot. 2004: p. 124.

[17] Citron DM, Goldstein EJC, Merriam CV, et al. Bacteriology of moderate to severe diabetic foot infections and in vitro activity of antimicrobial agents. Journal of Clinical Microbiology 2007;45(9):2819-28.

[18] Varaiya AY, Dogra JD, Kulkarni MH, et al. Extended spectrum Beta-Lactamase producing Escherichia coli and Klebsiella Pneumoniae in diabetic foot infections. Indian Journal of Pathology and Microbiology 2008;51(3):370-2. 
[19] Emily SB, Myrna MT. Prevalence and risk factors associated with Extended Spectrum $\beta$ Lactamase production among selected enterobacteriaceae isolates at the Philipinne general hospital. The Philippine Journal of Microbiology and Infectious Diseases 2003;32(4):1-11.

[20] Dang CN, Prasad YD, Boulton AJ, et al. Methicillinresistant Staphylococcus aureus in the diabetic foot clinic: a worsening problem. Diabet Med 2003;20(2):159-61.
[21] Hena JV, Growther L. Studies on bacterial infections of diabetic foot ulcer. African Journal of Clinical and Experimental Microbiology 2010;11(3):146-9.

[22] Cerveira JJ, Lal BK, Padberg FT, et al. Methicillinresistant Staphylococcus aureus infection does not adversely affect clinical outcome of lower extremity amputations. Annals of Vascular Surgery 2003;17(1):80-5. 